\title{
The Research Status of Bearing Seal of Cone Bit at Home and Abroad
}

\author{
Yi Zhou', Lin Wang ${ }^{2}$ \\ School Of Mechatronic Engineering, Southwest Petroleum University, Chengdu, 610500, China
}

\begin{abstract}
Cone bit drilling is the most important rock-breaking tool, its performance will directly affect the quality of drilling, drilling efficiency and drilling cost. High-speed roller bit bearing seal is the weakest link, but also wearing parts, is the most critical factor in determining the life of the high-speed roller bit. Field data statistical analysis showed that early damage caused by bearing failure drill $80 \%$ of the total failure of the drill bit, due to early failure and severe wear of the seal bearing $30 \%$ of the total failure of the bearing ${ }^{[1-2]}$. Sealing problem has become a serious impact speed cone bit drilling efficiency and drilling cost of technological bottlenecks, the current oil drilling project is urgently needed to solve the problem. Practice shows that current conventional cone bit bearing seal performance can not meet the requirements, especially in the high speed drilling, when lower seal life, sealing poor durability, seal wear, aging compared serious. Cone bits sealed condition very poor, including high temperature, high tempered medium, high load, and the size of a small sealed chamber, the working conditions and the environment will exacerbate the failure of the seal, but also to study the sealing tape to a lot of difficulties and challenges.
\end{abstract}

Keywords: Cone bit; Seal problems; Research status

\section{Cone Bit Bearing Seal Problems}

Sealing method currently used mainly rubber O-ring seal, floating seal bi-metal, a single metal floating seal, in recent years invented the double seal, but these are passive seal-tight manner, does not have the automatic discharge of sand functions in wells lower poor working conditions, severe seal failure, short seal life.

\section{(1) Rubber ring seal}

Rubber ring seal the biggest drawback is poor heat resistance properties and does not have exclusive sand, drill seal extremely harsh working conditions, including high temperature, high pressure, high tempered media, though, domestic and cross-sectional shape of the rubber ring to do a lot of research ${ }^{[3]-[5]}$, but the rubber ring wear property but it has not been solved. Especially at high temperatures, wear resistance of the rubber ring is even more serious, rubber brittle, hardened, abrasion resistance is greatly reduced, the seal will fail prematurely.

\section{(2) Metal floating seal}

Metal floating seal includes a bimetallic floating seal (Shown in figure 1.1) and a single metal floating seal (Shown in figure 1.2). Metal floating seal includes a primary seal and a secondary seal. Primary metal sealing surface of the sealing surface, the auxiliary seals are rubber O-ring seal. Metal floating seal the main problems: First, the primary sealing surface - metal contact surfaces can not be achieved after the deformation automatic wear compensation, once the particles into the mud, gradually increasing wear, the seal will lose its effective role, wear problems can not be resolved. Second auxiliary rubber ring seal -O remains of the rubber ring seal problem is the passive-tight manner, having no active discharge sands properties, high temperature so that wear and tear, a serious failure ${ }^{[6]-[10]}$.
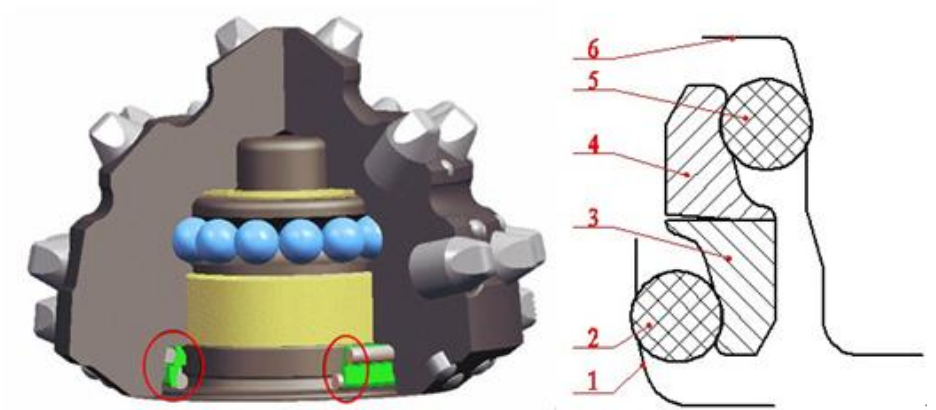

1- Bearing journal contour; 2- Static rubber ring; 3- Stationary metal ring; 4- Movable metal ring; 5- Movable rubber ring; 6- Contour cutters

Figure 1.1: Bimetallic floating seal structure 
International Journal of Science and Research (IJSR)

ISSN (Online): 2319-7064

Index Copernicus Value (2013): 6.14 | Impact Factor (2015): 6.391

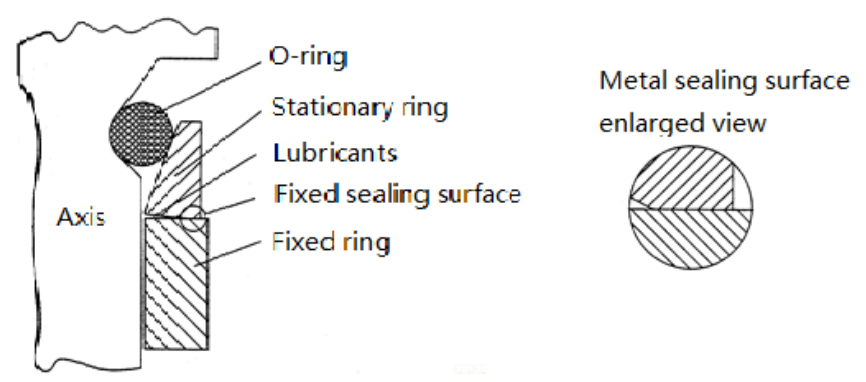

Figure 1.2: Single-metal seal structure

\section{(3) Double-sealed}

Double seals (Shown in figure 1.3) includes two seals, through the primary seal and a secondary seal to protect primary seals a seal, but the seal is still in the theoretical stage, whether it is suitable for high-speed roller bit and drill on site the application is not related reports, nor does it have automatic discharge of sand performance.

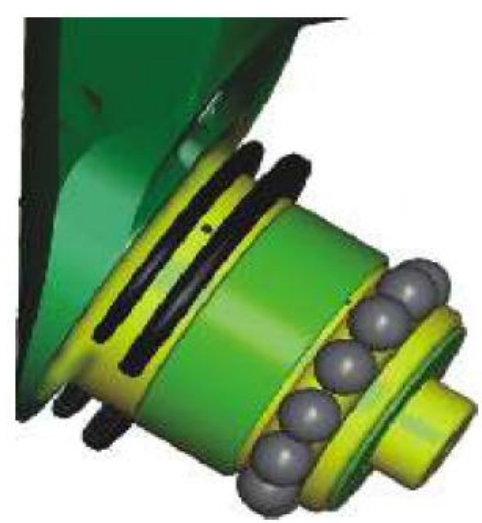

Figure 1.3: Double-sealed structure

\section{Research Status}

\section{(1) Annular radial seal}

1964 Hughes with dish wave of outsourcing rubber spring ring sealing member of the rolling bearing cone bit series of products into the market. The drill life expectancy has more than doubled over the drill bit is not sealed. But the poor reliability of this seal lubrication system. Later, O-ring rubber has been widely used, and evolved into different forms of seals, etc., but the rubber ring wear serious, serious failures, shorter life expectancy. To address bit bearing seal oil issues in 1981, Lanzhou Petroleum Machinery Research Institute Liu natural, Huang Lianying order to solve the bit bearing seal - oil issues, successful research two rubber seals, namely "O" type and rectangular section ring. Two rubber seals in the drill simulation conditions, the former can operate over 400 hours, which can be operated more than 800 hours, a good sealing property, a one-way valve which can be adjusted as desired range of pressure, adjusting reliable performance. Compact vacuum oiling valve structure, convenient operation ${ }^{[11]}$. In 1994, Luo Wei, He Qixiang and other commonly used seal for bearing drill ring radial seal failure causes the status quo and put forward the main factors affecting the sealing performance and reliability of the drill is to seal the sealing material and the pressure difference on both sides of the media associated sealing contact stress between surfaces, as well as manufacturing and assembly precision sealing system ${ }^{[12]}$. In
2003, according to Professor Yang Qiming Southwest Petroleum University tribological properties tricone bit of work, finite element analysis, the end face of the drill bit bearing seal combination radial structure were analyzed, whereby a new sealing design. Theory and Practice shows that this new combination seal structure can adapt to high-speed roller bit bearing seal development needs ${ }^{[13]}$.

\section{(2) Bimetallic floating seal}

At home and abroad for less bimetallic floating seal research in the later field application process, the lower seal life, and therefore not widely promoted. Because of its failure affected by many factors, although many manufacturers have also done a lot of experimental research drilling, but it is difficult to find the root cause of failure. Hughes invented the first bi-metal floating seal structure, in 1998, Liu Lei, Wen guards use interface based on the penalty function method, finite element method on the double metal seal structure numerical simulation analysis. Simulate the stress changes in the assembly and the work process, its structure design, equipped with a certain significance ${ }^{[14]}$. In 2014, Xiao Xiang, etc. using finite element analysis software Workhench analysis on the rubber O-ring maximum Mises stress and maximum shear stress distribution at different angles and chamfer radius of the support, and the support angles and chamfer radius were preferably, the rubber O-ring to solve the problem of stress concentration ${ }^{[15]}$. In 2014, Zhou Yi, who has been through simulation, experimental methods to study the case of two metal seal failure to find the root cause of the failure, and the improvement and optimization of a new structure, improve seal life ${ }^{[16]}$.

\section{(3) Single metal floating seal}

In 1987, Baker Hughes Christensen company first bimetal structure is applied to the floating seal cone bit bearing system, can significantly improve the speed of the drill work and life. Later, the company launched the first generation of a single metal floating seal (SEMS), the second generation single metal floating seal (SEMS2), the average life expectancy in the Gulf of Mexico drill (GOM) regions, more than 55 hours. Although scholars of its structure, mechanism, material constantly studied, but in practical application of its life remains low ${ }^{[17]}$. In 1991, Luo Wei, Guohong collar and other experimental method gives metal floating seal axial compression, analog-to-metal cone bit condition floating seal sealing properties were studied experimentally. Experimental results show that the metal floating seal having a small amount of leakage at high speed, the friction heat, long life and other advantages ${ }^{[18]}$. In 2004, Beijing Institute of Petrochemical Technology Department of Mechanical Engineering Zhang Baosheng and other cone bit in the successful application of a single metal floating seal structure key is to control the contact pressure between the seal faces. Application of advanced non-linear finite element analysis software Msc1Marc, combined with a single metal floating seal assembly structure finite element analysis of its sealing mechanism, to make practical application should pay attention to the problem, and discusses the structure, design parameters, materials, grease on sealing ability ${ }^{[19]}$. In 2008, Zhang Baosheng, Chen 


\section{International Journal of Science and Research (IJSR) \\ ISSN (Online): 2319-7064}

Index Copernicus Value (2013): 6.14 | Impact Factor (2015): 6.391

Jiaqing introduced the single metal sealing applications characteristics, lubrication model, computer-aided engineering (CAE) in theoretical research in the application of surface hardening technology in a single metal floating seal application, pointing out that the use of CAE technology to optimize seals argument is research and development of a single metal floating seal effective way. In 2009, he was floating through the establishment of new single-metal seal finite element model, comparative analysis of the effect of supporting rubber ring and pockets of different structures on the sealing surface of the contact pressure magnitude and distribution of improved dynamic seal surface contact force distribution, noted in static the sealing surface of the ring out of the slope parameters for dynamic sealing surface can effectively improve the contact pressure distribution and reduces the dynamic sealing surface wear. Later, in order to solve a single metal floating seal structure is complex and difficult research problem, an improved single metal floating seal structure (GSEMS), and the use of finite element software for the second generation single metal floating seal assembly process SEMS2 and GSEMS simulation results between the sealing surface with a similar force distribution and sealing ability, reducing the gap in the rubber between the stationary ring and a cone, with good sealing properties ${ }^{[20]-[22]}$.

\section{(4) Hydrodynamic seal}

Initially foreign MS Kalsi and Security jointly launched a hydrodynamic seal bearing drill bit, and later, in 1995, according to Luo Wei and other hydrodynamic lubrication theory, a novel hydrodynamic seal structure, and then under the spiral flow theory to flow between the seal faces as the control criterion, initially identified the type hydrodynamic seal structure parameters ${ }^{[23]}$. In 1995, the Petroleum University professor Chen Jiaqing seal on self test drill machine, for different types of dynamic seal friction properties were compared with the experiment, and then systematically carried out cone bit hydrodynamic seal friction properties and sealing performance test. Experimental results show that the new hydrodynamic seal friction characteristics, good sealing properties ${ }^{[24]}{ }^{[25]}$. In 1973, the United States has a hydrodynamic seal amount accounted for $40 \%$ of the total amount of oil seals, R.V.Brink and L.A.Horve developed waveform seal (Wave seal), the sealing performance superior to conventional hydrodynamic seal ${ }^{[26]}$.

\section{(5) Double-sealed}

Features dual seal technology is a technology proposed by Smith in 2006. Sealing system comprises two seals - the main seal and the secondary seal to protect the primary seal. Primary and secondary seals with different structures and composite materials to improve the wear resistance of the sealing system in high pressure, high temperature, corrosive downhole environments can maintain good durability and reliability, but the seal is still in the theoretical stage specific practical application without making further study. Since its launch date, material and structure of the sealing system in terms of both continuous improvement.

\section{Summary}

In summary, the study abroad seal for ordinary cone bit, the study of high-speed roller bit seal is also very little. With the cone bit bearing seal and cone bit more attention to the trend to high-speed development by, more and more domestic and foreign researchers hope to obtain good sealing performance and longer life of the seal structure, seal and bearing cone bit harsh work environment, limiting the development of sealing technology. Spiral Seal is a non-contact seals, non-contact work, wear almost zero, combined with the higher the speed, the better the spiral pumping action. Based on this, the spiral seal advantage will become more prominent. Domestic and foreign scholars have used the method theoretical research, simulation, experimental studies, the research work of sealing the spiral structure, sealing performance a lot, but the study in conjunction roller bit actual working conditions has not been reported.

\section{References}

[1] Z. Wang, Q. Peng, M. Su, S. Qi. Cone bit bearing system failure analysis [J]. Southwest Petroleum Institute. 1987 (03).

[2] Crease A. B. Windback seals-a simple theory and design method and the main Pratical limitations Proc. of 7 th ICSF. 1975.

[3] $\mathrm{Xu}$ Sheng. O-ring seals and Die [J]. Oil drilling machinery. 1985 (06).

[4] Ziyu Wang, Cone bit bearing system failure analysis [J]. Southwest Petroleum University .1987,9 (3): 72-86.

[5] X. Zhou, Z. Wang, J. Zhang. Cone bit bearing seal structure and typical failure of the main factors $[\mathrm{J}]$. Southwest Petroleum Institute, September 1990, 1-4.

[6] F. Chen, J. Chen. Wear Resistance of WC-Co Coating [J] .Roller Bit metal sealing ring surface coating. Surface Technology,2009,38(5):1-2.

[7] F. Chen, J. Chen. Advances in technology Roller Bit Metal Face Seal surface hardening [J]. New technologies, 2009,9: 98-10.

[8] J. Sun, K. Chi. Performance floating seal structure analysis [J]. Oil Field Equipment, 2006,35 (1): 14-18.

[9] B. Zhang, J. Chen. Improved roller bit SEMS2 single metal floating seal structure [J]. Oil machinery, 2010,38 (8): 5-7.

[10]B. Zhang, J. Chen. Research on single metal floating seal technology [J]. Lubrication Engineering, 2008,3 (3): 99-103.

[11] Tianran Liu. Three cone bit bearing seal Experimental Study [J]. Oil compensating system Oil Field Equipment, 1981,1-3 ,.

[12] W. Luo, Q. He. Metal cone bit floating seal research and design [J]. Petroleum Machinery, 1994, 22 (12): 16-19.

[13] Q. Yang, Y. Chen. High-speed roller bit bearing sealing design and finite element analysis [J]. Southwest Petroleum Institute. 2003 (06).

[14]L. Liu, W. Wen. Finite element analysis of double metal seal structure [J]. Lubrication Engineering, 2001,20 (6): 4-8. 


\section{International Journal of Science and Research (IJSR) \\ ISSN (Online): 2319-7064}

Index Copernicus Value (2013): 6.14 | Impact Factor (2015): 6.391

[15]X. Xiao, B. Chen, C. Sun, Y. Liu, Y. Xu . High-speed roller bit bearing bi-metal seal structure preferably Analysis[J]. Petroleum Machinery. 2014 (10).

[16] Yi Zhou, Zhiqiang Huang, Li Tan, Yachao Ma, Chengsong Qiu, Fuxiao Zhang,Yuan Yuan, Chunmei Sun, Liang Guo, Cone bit bearing seal failure analysis based on the finite element analysis,Engineering Failure Analysis,45(2014)292299.

[17] Leandro Carre, LarryW ilson, Jerry Cockerham, et al. Application of new generation large roller-cone bits reduces drilling costs in eastern Venezuela [C]. SPE 69617, Presentation at the SPE Latin American and Caribbean Petroleum Engineering Conference in Buenos Aires, Argentina, 25-28March 2001.

[18] W. Luo, H. Guo. Experimental study of high-speed roller bit floating metal seal [J]. Oil machinery, 1991,19 (10): 23-27.

[19]B. Zhang, J. Chen. Sealing mechanism metal cone bit single floating seal structure $[\mathrm{J}]$. Oil machinery, 2003,31 (2): 1-3.

[20]B. Zhang, J. Chen. Study [J]. A single metal floating seal lubrication and seal technology. 2008 (03)

[21] B. Zhang, J. Chen, Y. Zhen. Improved roller bit SEMS2 single metal floating seal structure $[\mathrm{J}]$. Petroleum Machinery. 2010 (08).

[22]B. Zhang, J. Chen. Roller Bit floating seal research [J] with a new single-metal petroleum machinery. 2009 (11).

[23] J. Chen, W. Luo. Cone bit hydrodynamic seal structure parameter determination and vision $[\mathrm{J}]$. Oil Field Equipment. 1995 (02).

[24] Jiaqing Chen. Research cone bit bearing radial seal [J] Lubrication Engineering, 1995 (3): 17-22. [25] J. Chen, W. Luo. Experimental study of cone bit hydrodynamic seals [J]. Oil Field Equipment. 1995 (05).

[25] Brink RV.Horve LA.Wave seals - a solution to the hydrodynamic compromise $\cdot$ Lubrication Engineering $[\mathrm{J}]$. American Society of Lubrication Engineers (ASLE), 1973, 29(6): 265-270.

Volume 5 Issue 6, June 2016 www.ijsr.net 